\title{
SISTEMA ÚNICO DE ENSINO: O DESAFIO DA CONSTRUÇÃO E DA AMPLIAÇÃO DO ESPAÇO PÚBLICO DE DIREITOS NA ESCOLA PÚBLICA DE MATO GROSSO*
}

\author{
GESUINA LECLERC
}

\begin{abstract}
RESUMO: Destacamos uma experiência de intervenção do Sindicato dos Trabalhadores no Ensino Público de Mato Grosso (Sintep-MT) para propor ações progressivas, de longo prazo, naquele Estado. Uma experiência inédita. O sindicato empenha-se na regulamentação do dispositivo constitucional de 1989 que determina a integração progressiva das redes estadual e municipais num Sistema Único de Ensino, durante o governo Dante de Oliveira. Criaram-se mecanismos para incorporar a população usuária da escola pública (pais, mães e estudantes) nas tomadas de decisão sobre as Políticas Educacionais, visando a auxiliar na construção e na ampliação do espaço público de direitos. Não houve a regulamentação e os mecanismos não estão sendo consolidados; é preciso retomar a experiência de modo crítico e propositivo. O sindicato está mais qualificado para esse protagonismo.
\end{abstract}

Palavras-chave: Projeto político-pedagógico. Políticas públicas. Estado. Sindicalismo. Democracia.

\section{A ONE AND ONLY SCHOOLING SYSTEM: THE CHALLENGE OF CONSTRUCTING AND WIDENING THE PUBLIC SPHERE OF RIGHTS IN MATO GROSSO'S PUBLIC SCHOOLS}

ABSTRACT: We highlight an unheard-of experience involving the Union of the Public Teaching Workers of Mato Grosso (Sintep-MT), which promotes long term progressist actions, within that State. Under Dante de Oliveira's Government (1994-1998), this Union has been striving to regulate the 1989 constitutional clause that determines a progressive integration of the network of state and municipal schools into a one and only Schooling System. Mechanisms have been created to involve the population that uses public schools (parents and students) in the deliberation and decision about educational policies; these mechanisms have been designed to favour the construction and the widening of the public sphere of rights. The regulation came to nothing and the mechanisms are still to

\footnotetext{
* Adaptado de dissertação de mestrado em Educação Popular, defendida em 1999 na Universidade Federal da Paraíba. Agradecimentos são devidos à Capes, aos educadores e educadoras da direção do Sintep-MT, em especial os que fizeram a gestão "Educação no Centro das Atenções" (19941997) e ao João Monlevade; aos professores(as) Maria Deusa e José Neto pelas primeiras críticas; a Luís Augusto Passos pela orientação e, especialmente, aos dois pareceristas anônimos desta revista.

** Professora na Educação Básica Pública da Rede Estadual de Mato Grosso e mestra em Educação Popular pela Universidade Federal da Paraíba. E-mail: aleclerc@openline.com.br
} 
consolidate. Nowadays, this frustrated experience should be resumed in a critical way, with new proposals. The Union is now more experienced and should reopen the process with the intention to achieve it.

Key words: Political-pedagogical project. Public policies. State. Unionism. Democracy.

7 Constituição Estadual de 1989, em Mato Grosso, determina que o estado promova o reordenamento do Sistema Público de Ensino, provendo as condições técnico-financeiras para integrar os Sistemas Municipais e Estadual num Sistema Único de Ensino. Em 1996, foi empreendido um debate para a criação e a implantação do Sistema Único, a partir de uma agenda comum entre o Sindicato dos Trabalhadores no Ensino Público de Mato Grosso (Sintep-MT) e o governo estadual, com a mobilização e a participação da população usuária da escola pública (pais, mães e estudantes), em nível escolar, municipal e estadual. O governador Dante de Oliveira, por meio da assinatura do acordo Escola Pública: Compromisso por Mato Grosso, que encerra uma greve de 11 dias com 32 horas de ocupação da Secretaria de Estado da Educação (Seduc), institui as premissas iniciais para o reordenamento.

A proposta do governo, sob coordenação da Seduc, é denominada de Sistema Unico Descentralizado de Educação Básica (Sudeb) e foi o termo de referência para os debates. O sindicato propõe modificações estruturais ao documento do governo quanto aos eixos constitutivos, o processo de criação e a implantação do novo sistema. As modificações almejaram um Sistema Único de Educação Pública Básica para Mato Grosso e combatem a descentralização que pretendia denominar o sistema. As propostas serão debatidas nas Conferências Deliberativas convocadas pelo governo, onde as emendas modificativas são aprovadas pelo voto dos conferencistas, superando as proposições do termo de referência do governo. Entretanto (ou por isso mesmo) o governo, promotor do processo, desconsidera o resultado dos trabalhos das Conferências e desassocia sua política educacional da viabilização do Sistema Único. Nessa altura o governo federal já definia o Fundo de Manutenção e Desenvolvimento do Ensino Fundamental e de Valorização do Magistério - Fundef - como novo ordenamento do financiamento da educação.

Buscamos neste artigo contextualizar as concepcões de Sistema Único de Educação Pública Básica em disputa, mediadas pela necessidade da construção e da ampliação do espaço público de direitos na escola pública. ${ }^{1}$ Consideramos os problemas dos mecanismos para tomada de decisão no interior do estado e do modo como se relacionam o estado e o Sintep- 
MT no campo das políticas públicas, num contexto de enfraquecimento das organizações sindicais, de incipiência e/ou ausência da organização dos usuários da escola pública (pai, mãe e estudantes) para exercer pressão. $^{2}$

\section{Antecedentes}

No ano de 1994, uma coalizão de dez partidos, denominada Frente Cidadania e Desenvolvimento (PDT, PSDB, PMDB, PT, PC do B, PPS, PSB, PSD, PMN, PV) elegeu Dante de Oliveira (PDT/PSDB) governador do Estado de Mato Grosso. O programa de governo comprometia-se com a organização de fóruns de desenvolvimento, envolvendo a representação dos diferentes setores sociais na definição das políticas, e com o princípio cooperativo para somar recursos e energias, minimizar custos e assegurar o controle social na implementação das políticas; adotava a educação, a energia e a estrada como suas políticas estruturantes (Plano de Metas 1995-1998: 1994). Pelos propósitos firmados no plano de governo, pela possibilidade de articulação da hegemonia das forças de centro-esquerda na sustentação do governo, e pelo esforço mobilizatório e de proposição empreendido pelo sindicato na definição da política educacional, o governo Dante de Oliveira aglutinava as condições políticas para promover um Sistema Único de Educação, conforme determina a Constituição Estadual no seu Artigo 244:

Os Sistemas Estadual e Municipais de Ensino passam a integrar o Sistema Único de Ensino.

Parágrafo Único: Ao Estado caberá organizar o sistema de ensino e prestar assistência técnica e financeira aos municípios para gradual integração num Sistema Único de Ensino na forma da Lei.

Primeiro a reforma do estado, depois a reordenação da educação, da saúde e da segurança

Em 1995, o governador Dante de Oliveira lança mão de um Plano Emergencial, elaborado exclusivamente por uma equipe estratégica, com vistas a realizar a transição de governo. A pauta principal era o pagamento da dívida pública para com o governo federal, nos termos do Conselho Monetário Nacional, e teve como diretrizes: o ajuste de quadro de pessoal com a demissão de 7.100 funcionários (dos quais 6.300 eram da educação), a linha de crédito para programa de demissão voluntária e o 
programa de privatização, as medidas de apoio à reestruturação, ao ajuste fiscal e à reforma do estado. Simultaneamente o governador tratou da articulação de uma sustentação de governo ampliada entre a correlação de forças no nível da Assembléia Legislativa. Buscou conciliar de um lado os deputados do seu arco de alianças que se dispersavam em torno da disputa pela Mesa Diretora da Assembléia Legislativa e, de outro lado, negociar com as forças que não participaram da coalizão - (a divisão é meramente didática), conforme expressa o deputado Renê Barbour: "Somos um grupo de deputados - empresários com respeitabilidade em nosso estado e, talvez, possamos ser mais úteis ao governador do que sua própria bancada, na votação de matérias que lhe darão condições de administrar com êxito o nosso Estado de Mato Grosso” (jornal A Gazeta, 24 jan. 1995).

As eleições para Mesa Diretora acabaram na polícia. A deputada Serys (PT) é agredida pelo deputado José Riva (PMN), após pedir anulação da votação. As 13 cédulas dadas à chapa vencedora (encabeçada pelas forças do governo derrotado) estavam marcadas para posterior identificação dos votantes, quebrando o princípio do voto secreto. A segurança no plenário da Assembléia Legislativa estava reforçada por guarda-costas particulares de alguns deputados durante a eleição, conforme denunciou o deputado Francisco Daltro (PDT): "Foi um terrorismo ostentado com seguranças, verdadeiros capangas policialescos, extraquadro da Assembléia, contratados por alguns deputados para ficar dentro do plenário" (jornal A Gazeta, 2 fev. 1995).

Havia sempre um programa muito emergencial, a "arrumação da casa”, como costumava dizer o governador; o trabalho da equipe estratégica substituiu a necessidade da constituição dos fóruns de desenvolvimento e as articulações políticas do governador com o parlamento substituíram a importância dos fóruns partidários. Em 1996 o governador Dante deixa o PDT e filia-se, juntamente com sua equipe estratégica, ao PSDB, angaria novos apoios vindos das forças políticas derrotadas pela conformação original da Frente Cidadania e Desenvolvimento, assim obtém maioria no parlamento e também estabelece um canal direto com o governo federal. O PT rompe com o governo, alguns setores do PT (inclusive saídos do próprio movimento sindical representado pelo Sintep) que ocupavam cargos no governo se filiam ao PPS, permanecendo nos cargos. Dentro da nova conformação da coalizão, as forças de centro-esquerda que permaneceram foram incapazes de impor uma política diferenciada dos programas comandados pelo governo federal. O PMDB, apesar de se manter no governo por 
meio do vice-governador Márcio Lacerda, irá disputar as eleições numa composição com o PFL, apoiando o ex-governador Júlio Campos, contra o governador Dante de Oliveira. Fora da coalizão o PT-MT não pôde ainda viabilizar uma política de alianças capaz de fazer frente à nova direita, representada pelo governador Dante de Oliveira que se reelege em 1998. ${ }^{3}$ Ocasião em que a disputa eleitoral privilegiou a pauta da educação, principalmente porque o então presidente licenciado do Sintep, Carlos Abicalil, era candidato a governador pelo PT, com reconhecida competência para o debate técnico e filosófico das questões educacionais. Reconhecida e publicizada até pelos adversários. O candidato Júlio Campos, do PFL, em debate na televisão, valendo-se da dinâmica em que os candidatos fazem perguntas entre si, fez tal reconhecimento e em seguida perguntou a Carlos Abicalil se este aceitaria o convite para ser o secretário de Educação de seu governo. Dante de Oliveira não fez diferente, em $1^{\underline{a}}$ de outubro, dois dias antes das eleições: em ato solene, sancionou as Diretrizes Educacionais para Mato Grosso (a Lei do Sistema Estadual de Ensino, Lei da Carreira dos Profissionais da Educação Básica e Lei de Gestão Democrática), descongelando os salários dos professores para discursar em palanque que havia atendido às reivindicações do Sintep e de Carlos Abicalil. No entanto essas diretrizes passam longe da reformulação requerida e debatida para a constituição do Sistema Unico, e não tocam nas desigualdades entre os Sistemas Estadual e Municipais, por exemplo nos pisos salariais desiguais, na desigualdade e na falta de uma política de carreira, de formação continuada e de gestão democrática.

Dois políticos com mandatos passaram a exercer o comando da Secretaria de Estado da Educação, o deputado federal Antônio Joaquim (1998-1999) e o deputado estadual Carlão (2001). Para acomodar os interesses de políticos como o ex-secretário de Educação Osvaldo Sobrinho, contra quem o próprio Dante de Oliveira havia disputado sua primeira eleição para governador em 1994, rearranjando os mandatos na Câmara Federal e na Assembléia Legislativa. Revive-se então a relação umbilical entre o clientelismo e a educação.

\section{A cultura do clientelismo político como via de acesso ao estado}

Continuam ainda mínimos os canais de representação política ante o estado e os teóricos e agentes preconizadores de modernização são ainda fascinados pelos modelos tecnocráticos que lhes parecem dotados da impessoalidade necessária para definir o espaço público (Chaui, 1994a). O governo do ex-deputado federal Dante de Oliveira, conhecido pela 
proposição da emenda das "Diretas-já” de 1984, continua sendo um exemplo paradigmático sobre como adotar um discurso de democratização e participação popular e uma prática de governo tradicional, que utiliza os mecanismos de tomada de decisão aprendidos com a liberalização do regime militar, sem democratização de fato, feita pela chamada transição por cima.

Os esforços do sindicato para intervir na definição da política educacional de modo a criar e valorizar espaços críticos, públicos, de interlocução são expressão da tentativa para se constituir um novo centro decisório (Genro, 1997) que, juntamente com o Poder Executivo e Legislativo, venha democratizar a ação política e integrar os cidadãos comuns num novo espaço público, capaz de dar visibilidade e transparência ao poder. Como tarefa de um sindicalismo gerado à medida que as instituições dos serviços públicos vão se tornando mais impessoais, sendo dominadas por comissões e regulamentos, superando as relações informais que deram lugar a concursos para admissão e ensejam o enfraquecimento do protecionismo e do clientelismo que envolve a carreira pública (Rodrigues, 1996); num processo histórico recente (e no Mato Grosso com profundas diferenciações regionais), a partir do final do regime militar, da década de 70 para a frente num estado de base econômica agrária e latifundiária.

Reconhecemos com Avelar que as vias de acesso ao estado continuam se dando por meio dos "anéis burocráticos" e de grupos privados que interagem com os órgãos governamentais, principalmente na educação de onde o segmento tecnoburocrático recebe pressões (a relação do favor), vindas dos canais personalizados, constituídas nas redes de relações locais, que se fazem representar. Majoritariamente os partidos políticos são ainda cinturões de transmissão dos interesses das oligarquias regionais e locais. Não se pode pensar novos processos de gestão das políticas públicas fora de um processo de mudança política e cultural, como um conceito amplo que envolve um confronto de projetos políticos (1996a). Isso sem considerarmos ainda a complexidade dos conflitos e as discriminações de gênero, etnia e de posição social, econômica e cultural que medeiam, por exemplo, as relações locais e a constituição de representação política nas experiências de gestão democrática das unidades escolares.

\section{A autocrítica necessária quanto ao corporativismo}

$\mathrm{Na}$ construção da agenda comum que envolveu o Sistema Único devemos publicizar a complexidade das relações que se estabelecem no sindicato, suas tentativas para identificar e modificar a sua dinâmica interna, 
seu contexto corporativo-organizativo ante o Estado, reconhecendo: a) a relação entre uma direção sindical político-ideologicamente posicionada (e às vezes radicalizada e sectarizada) com o conjunto da categoria que permanece distante do conteúdo político-ideológico pautado; b) a tendência a tomar para si, quase como se tivesse direitos exclusivos, a defesa da educação, das suas questões mais gerais às mais específicas; c) a democracia somente para os que são mais politizados, para uma parcela pequena do professorado. A democracia do sindicato é assim uma democracia para uma parcela de $10 \%$ mais ou menos, porque aqueles que não participam assiduamente se deparam, no fim das contas, com um conjunto de regras e normas que funcionam para aqueles que chamamos de militantes, mas são desconhecidas pelo conjunto; d) o relacionamento direto com a não-organização dos pais e mães para exercer algum tipo de pressão coletiva, com o limite e mesmo a ausência de uma linguagem para falar com os diferentes, os estudantes e suas famílias (Cunha \& Milhomem, 1996). É preciso ainda assumir as considerações de Kenski sobre a constituição histórica do magistério que se desenvolveu como função inerente à prática dos religiosos, tendo sido assumida pelo estado, mas mantendo todas as formas e os moldes já existentes no modelo clerical de ensino. A carreira docente não se instituiu a partir de uma concepção corporativa do ofício mas a partir de uma concessão do Estado que garante aos professores um status profissional particular, desvinculado dos poderes locais, onde se dá o exercício da função e subordinado social e politicamente à ideologia e aos interesses particulares do governo. $\mathrm{O}$ isolamento social dos professores, a indefinição profissional que paira sobre a carreira e quanto ao grau de liberdade de atuação profissional, dependente das normas estatais e autônomo na escolha de suas próprias práticas pedagógicas, geram o comportamento que tende a fortalecer associações que possam coordenar o movimento em defesa de seus interesses e a luta por suas reivindicações profissionais, principalmente diante do Estado (1995).

\section{O projeto de sociedade}

As políticas viabilizadoras do Sistema Único exprimem um projeto de organização social a partir do qual o dispositivo constitucional foi inscrito na Constituição Estadual e com o qual o Sintep-MT está relacionado. Esse projeto é uma construção histórica, trespassado por conflitos, antagonismos e lutas, em que a questão do poder está sempre presente, exigindo ser este equacionado e socializado; colado nele a escola pública representa um legado de idéias que podem: estimular uma 
concepção de cidadania, tendo como dimensão central a participação no poder, e desempenhar um papel cultural crítico, vivenciados nela mesma. A concepção de cidadania é indissociável da possibilidade ou não da democracia e da igualdade política, numa sociedade capitalista, baseada na desigualdade social e econômica (Arroyo, 1996a); sociedade cujo objetivo fundamental é produzir para acumular, concentrar e centralizar capital (Frigotto, 1996a). Nessa sociedade a cidadania é tratada como privilégio de classe, e como uma concessão regulada e periódica da classe dominante às demais classes sociais, as assimetrias sociais e pessoais são transformadas em desigualdades e em relações de hierarquia e as leis são consideradas inócuas, feitas para serem violadas (Chauí, 1994b). Na expressão de Sacristán "o desenvolvimento de um sistema público forte tem sido tardio para nós” (1996), a esfera pública nunca chegou a constituir-se como pública, definida sempre e imediatamente pelas exigências do espaço privado, de sorte que a vontade e o arbítrio são as marcas do governo e das instituições "públicas” (Chauí, 1994c).

\section{Cenários e tendências}

Desestatização de amplos setores dos serviços públicos necessários sob responsabilidade do Estado

A proposição do sistema público de ensino, assim como a do conjunto das políticas públicas, tem sofrido grandes restrições desde o declínio do Estado de bem-estar social, um modelo de Estado que garantiu "tipos mínimos de renda, alimentação, saúde, habitação, educação, assegurados a todo cidadão, não como caridade, mas como direito político, e desse modo reivindicados pelos cidadãos” (Bobbio, 1983). Esse modelo foi desenvolvido numa concepção liberaldemocrática que vinculou o Estado à gestão da força de trabalho (reconhecendo direitos sindicais e políticos da classe trabalhadora) e às modalidades de acumulação do capital, numa sociedade marcada pela industrialização e pela urbanização. Expandiu-se a partir da Segunda Guerra Mundial realizando-se diferentemente nos países capitalistas da Europa e nos Estados Unidos e Canadá. A abordagem das questões sociais, políticas e econômicas do capitalismo que defende a liderança do Estado na promoção do crescimento, do bem-estar material e da regulação da sociedade civil, o keynesianismo, justificou que o Estado tivesse o controle de áreas estratégicas: petróleo, energia, minérios, telecomunicações, como meio para promover o pleno emprego como atendimento de um direito do cidadão. O Estado, por 
essa abordagem, torna-se, ele próprio, um produtor e passa a implementar uma série de impostos progressivos para poder estimular determinados setores com subsídios, garantir as condições gerais de funcionamento da produção capitalista e para dar respostas à organização e reivindicação da classe trabalhadora num contexto de ampliação do bloco socialista (Frigotto, 1996b). Essa forma de regulação social, que pode ser compreendida ainda como Estado Previdenciário ou regulação social fordista, perdeu coesão no final dos anos 70, quando a ordem internacional, ancorada pelo dólar norte-americano, deu lugar a uma finança internacional sem regulação. Paralelamente à falência do chamado socialismo real. Hoje se caminha no sentido inverso, que vai da restrição do bem-estar e da democracia ao darwinismo social conforme as políticas neoliberais que se tornaram hegemônicas no ideário das elites políticas, tecnólogas e econômicas (Silva \& Ianoni, 1999). O Estado neoliberal é estabelecido por mercados abertos e tratados de livre comércio, redução do setor público e diminuição da intervenção do Estado na economia e na regulação do mercado - supõe um estado de coisas no qual a distribuição ideal dos recursos produtivos pode ser alcançada pela competição, não há proteção nem perdão para os que empatam seu capital ou seu trabalho; a luta cruel pela sobrevivência seleciona os mais eficientes por meio da falência dos menos eficientes (Keynes, 1984).

O Estado de bem-estar social no Brasil não chegou a concretizarse. No cenário de seu enfraquecimento é que são estabelecidos os marcos de esforços reformadores inscritos na Constituição de 1988. A busca por novos espaços de participação consubstancia-se pela definição no texto constitucional de mecanismos ativadores da publicização na formulação e na gestão das políticas públicas. Entretanto mal os direitos são regulamentados encaminha-se o processo de reforma constitucional. A desestatização em curso e o Plano Real foram implementados sob a retórica de realizar o ajuste estrutural do Brasil, na perspectiva de integração competitiva na economia globalizada. ${ }^{4}$ As regras desse ajuste são aquelas que conhecemos como "Consenso de Washington" (denominação do plano de medidas de ajustamento das economias periféricas conforme reunião ocorrida em Washington em 1989, sob o comando do Fundo Monetário Internacional, do Banco Mundial e de outras agências). $\mathrm{O}$ ajuste estrutural é empreendido sob a perspectiva de que não há outra alternativa para os países a não ser a de ajustar-se à reestruturação produtiva promovida pela globalização excludente, por meio da desregulamentação (mínima existência possível de leis 
que garantam direitos), da descentralização/autonomia (delegação de responsabilidades antes da União aos estados, aos municípios e às escolas) e da privatização (Frigotto, 1996c).

$O$ recrudescimento do desenvolvimento excludente e o desafio de manter os serviços públicos necessários, sob responsabilidade do Estado

Para Frigotto é no plano ético que as políticas neoliberais, ao situar o mercado como definidor fundamental das relações humanas, acabam por naturalizar a exclusão sem culpa. Cabe aos educadores compreender como tais processos são aplicados à escola e como combatê-los. Tarefa que requer uma capacitação técnica e científica para o ser dirigente, tendo locus específico e adequado à universidade e sendo privilegiadamente exercida nos processos coletivos como o sindicato, entre outros (1995a). Nessa capacitação temos presente o problema das novas tecnologias. Segundo Leite as inovações tecnológicas dizem respeito a um conjunto de modificações sociais e econômicas que têm sido consideradas como constituintes de um novo modelo econômico - aplicam-se, em escala global ao mercado, nas regras de negociação coletiva, na reorganização dos departamentos das empresas e na reestruturação do Estado. As conseqüências sociais são conhecidas pela supressão duradoura e estrutural do emprego e pela transformação radical da mão-de-obra que permanece empregada. Mas o desenvolvimento tecnológico não pode ser pensado como o único fator a influenciar a organização do trabalho e não é incompatível com a manutenção do emprego. A tecnologia deve ser considerada como expressão de uma correlação de forças (Leite, 1994), na qual o sindicato está implicado.

\section{Um Sistema Único de Ensino e a proposição do modelo de Estado democrático}

O Sistema Único de Ensino proposto está baseado na idéia de auxiliar a constituição do espaço público de direitos na escola pública como parte indissociável do processo de democratização da sociedade mato-grossense. Nessa concepção a democratização almejada é pensada pela via do fortalecimento do Estado e da sociedade civil, pela inscrição dos interesses das maiorias na tomada de decisão política. Consideramos com Bobbio que regime democrático compreende primariamente um conjunto de regras e procedimentos para tomada de decisão coletiva, em que está prevista e facilitada a participação mais ampla dos interessados, sob o ponto de vista do direito, pensando em primeiro lugar nas leis fundamentais, capazes de 
estabelecer não aquilo que os governados devem fazer, mas de submeter os próprios legisladores à normas vinculatórias (1986). Na tradição gramsciana o Estado comporta duas esferas: a sociedade política, ou Estado no sentido estrito da coerção (para adaptar as pessoas à produção e ao tipo de economia de uma dada época), e a sociedade civil (os sujeitos sociais que estabelecem a correlação de forças que torna visíveis os conflitos e que viabiliza consensos), constituída pelo conjunto das organizações responsáveis pela elaboração e/ou difusão das ideologias, como os sindicatos, os partidos, as igrejas, o sistema escolar, a imprensa e os meios de comunicação de massa, entre outros. No sentido estrito o Estado identifica-se com o governo pelas funções coercitivas e econômicas (exército, polícia, administração e burocracia). Mas essa função coercitiva é inseparável do papel educativo do Estado que procura adequar o aparelho produtivo e a moralidade das pessoas, para criar um modo de vida. Assim o Estado realiza-se de modo ideológico. O Estado é a condensação de uma correlação de forças e envolve os interesses e grupos sobre os quais a hegemonia se exerce: é todo o conjunto de atividades teóricas e práticas com as quais a classe dirigente justifica e mantém não somente sua dominação, mas também consegue obter o consenso ativo dos governados (Gramsci apud Buci-Glucksmann, 1980). Quando nos comprometemos com o conceito ampliado de Estado ampliado não estamos deslocando o enfoque de um embate econômico. Sabemos que para ter o Estado atuando na definição da política educacional não se pode atribuir à educação o poder que ela não tem. Não estamos é negando a ela qualquer poder (Freire, 1997).

\section{Os recursos para o reordenamento do sistema}

A viabilidade do Sistema Único de Educação Pública Básica, debatida quanto à capacidade financeira do Estado de Mato Grosso, pode ser demonstrada sob diferentes pontos de vista - do que já vem sendo realizado, do que ainda pode ser praticado com os recursos vinculados e do que pode ser praticado incluindo o esforço de uma política fiscal com objetivos e metas a serem alcançados, a médio e longo prazos, para ampliar a receita - com muitas ressalvas importantes. A principal delas trata da destinação constitucional. A Constituição Estadual mato-grossense, em seu artigo 245, determina que o estado e os municípios apliquem, anualmente, nunca menos de $35 \%$ da receita resultante de impostos e transferências na manutenção e no desenvolvimento da educação escolar. Como isso nunca foi posto em prática há quem proponha a modificação para os 25\% da Constituição Federal, o que também não é praticado. 
O secretário Valter Albano acredita que no Mato Grosso uma readequação e otimização dos recursos entre as esferas de governo são suficientes para um Sistema Único - se considerados o nível de expansão das redes e da oferta de vagas (1995). Exemplifica, retrospectivamente, que era preciso compartilhar grau de atendimento com volume de recursos destinados pela mesma Constituição. Por não se atribuir, na mesma proporção, à prefeitura e ao estado a responsabilidade de atendimento, criou-se a disparidade da falta de eqüidade entre essas esferas. O município de Itiquira, atendendo pouco mais de 100 alunos, representava o $5^{\text {a }}$ orçamento de ICMS do estado, ao passo que o município de Terra Nova do Norte, com 2.500 alunos, representava o 43aㅡ orçamento de ICMS. Em Terra Nova do Norte não havia como se pagar ao professor mais do que a metade do salário mínimo; em compensação em Itiquira poder-seia pagar ao professor quase 3.000 dólares (Albano, 1998).

Se é possível o reordenamento do sistema já em tais condições - sem eximir o governo federal, sem se recair na adesão às propostas fáceis de promoção automática, rebaixamento das exigências, empobrecimento dos conteúdos para barateamento dos custos da educação popular (Escola Plural, 1994) -, possibilitar-se-ia uma margem para novos investimentos, pela efetiva aplicação dos recursos constitucionalmente destinados à educação. Mas isso não mostra como conciliar o atendimento, a ampliação da oferta a crianças, jovens e adultos ainda fora da escola. Nem muito menos aponta para uma qualidade mais descritiva em termos de equipamentos, instalação física, materiais e de valorização profissional do magistério (Sintep-MT, 1996). O primeiro passo defendido pelo Sintep-MT, para tratar dos recursos para o reordenamento do sistema de modo global, é a realização de um Censo Educacional, para construir um retrato da educação no MT e consubstanciar uma política de investimentos e a valorização social, mediante objetivos explicitamente definidos e publicizados.

Reordenamento do financiamento da educação com maior disputa pelos recursos públicos

Os problemas da educação, discutidos a partir dos salários dos professores, de início colocavam o sindicato numa posição bastante fragilizada. Era facilmente acusado de só brigar por salários. Os prefeitos diziam que o salário não era um problema deles, porque eles até pagavam mais (e muitas vezes muito mais) que o governo do estado. O governo do estado dizia que os prefeitos pagavam mais porque atendiam menos alunos do que podiam e deviam. O governo do estado fixou o número 
de matrículas para as escolas estaduais, deixou de atender a pré-escola, dividiu a educação básica (separou em ensino fundamental e ensino médio), polarizando as escolas. No meio do ano letivo mandou juntar salas de aula. Muitos alunos matriculados tinham desistido. Houve fechamento de salas de aula, de turnos e até de escolas em vários municípios. Foram criados programas de parceria com alguns municípios. Nem todos os prefeitos quiseram. Algumas parcerias foram feitas assim: se o prefeito abrisse vagas para turmas de $5^{\circ}$ até a $8^{\circ}$ série e as aulas funcionassem nas escolas do município, o governo do estado pagava os professores daquelas turmas e o prefeito complementava os salários até o valor pago aos professores lotados naquela prefeitura. Se o prefeito quisesse oferecer o $2^{\underline{a}}$ grau, havia um grupo itinerante de professores da rede estadual que ministraria aulas. O secretário de Educação mandava o grupo e o prefeito oferecia alojamento, alimentação e complemento salarial para aqueles professores, de acordo com a capacidade do município.

As bases institucionais que deram suporte ao debate do Sistema Único podem ser configuradas em dois momentos, o primeiro durante a gestão do secretário Valter Albano (1995), na dinâmica de elaboração do Plano Decenal de Educação para Todos. A Confederação Nacional dos Trabalhadores da Educação (CNTE), entidade à qual o Sintep-MT é filiado, participou da criação e da composição do Fórum Permanente de Valorização do Magistério, da Educação Básica e da Qualidade de Ensino pelo governo Itamar Franco. O Sintep-MT implementou as estratégias para cumprimento do Acordo Nacional e Pacto pela Valorização do Magistério e Qualidade da Educação, resultante dos estudos do Fórum - um Programa de Emergência para Profissionalizar o Magistério (que sobreviveu apenas da segunda quinzena de julho de 94 a outubro de 95). A CNTE empreendeu uma vigorosa luta (com acirrados debates e divergências internas ao seu movimento) para disputar o conteúdo da Valorização e Qualidade, ante o governo federal, orientando suas afiliadas para exercerem pressão e criarem espaços de discussão locais. Os pressupostos da Valorização e da Qualidade são a Formação Inicial e Continuada, o Piso Salarial Profissional Nacional como referencial do vencimento inicial dos Planos de Carreira, a Jornada de Trabalho Integral, com pelo menos $25 \%$ de horas dedicadas a planejamento docente, estudos, avaliação, reuniões, trabalho interdisciplinar. ${ }^{5}$ Os mecanismos de negociação empreendidos entre o governo do estado e o Sintep-MT basearam-se, inicialmente, na instalação do Colegiado Estadual pela Valorização do Magistério e da Qualidade de Ensino, e na nomeação da Comissão Paritária constituída entre o governo do estado e o Sintep-MT 
para apresentar proposta de reestruturação da carreira, do piso salarial profissional e de profissionalização do magistério. Os mecanismos contribuíram para que o sindicato criasse espaços conseqüentes onde denunciou e anunciou suas posições quanto aos objetivos socioeconômicos implicados nos compromissos da Conferência Mundial de Educação para Todos. Preconiza-se a adequação dos países à globalização econômica. Porque se globalizam mercados, falando-se no fim das fronteiras e na hora de viabilizar um Sistema Único de Ensino, não se consegue derrubar os muros que separam uma escola municipal e uma escola estadual?

O segundo momento é configurado pela desativação do Fórum pelo governo Fernando Henrique e pelo rompimento do acordo em outubro de 95, pela concepção unilateral e instauração da Lei do Fundef, que alteraram decisivamente as condições institucionais para o reordenamento do sistema público de ensino no Mato Grosso. O governo estadual, poor intermédio do novo secretário, Carlos Maldonado, apresentou uma proposta de Sistema Único Descentralizado de Educação Básica que nortearia o reordenamento do sistema (desconsiderando os fóruns já constituídos), em meio a congelamento e atraso salarial. Isso desencadeou a greve que resultou no acordo entre o sindicato e o governo do estado, assegurando: a reorganização do sistema, a automatização dos recursos constitucionais de modo a garantir absoluta segurança e transparência no trato dos ativos financeiros da educação, a reestruturação do Fundo Estadual de Educação transformando-o em Fundo Estadual de Manutenção e Desenvolvimento de Educação Básica, e o aprofundamento do debate em torno da viabilidade da implantação da Fundação Educacional de Mato Grosso.

Limites para uma agenda comum: O Sistema Único "Descentralizado" de Educação Básica ${ }^{6}$

O termo de referência para o debate, denominado "Sistema Único Descentralizado de Educação Básica” (Sudeb), submetido à modificação durante as Conferências, conforme expressão do próprio documento, visava a colocar a unidade escolar como foco da reorganização do sistema, tratando-se não de uma reforma, mas de uma transformação estrutural no modo de pensar, planejar, implementar e gerir a educação básica no Estado de Mato Grosso. A centralidade focal da escola objetivava fazer dela um espaço autônomo para o exercício decisório nas esferas administrativa, financeira, pedagógica e de gestão de pessoal, financiada pelos recursos estatais. O Sudeb pretendia iniciar um processo de 
escolarização com o objetivo de fazer a escola cidadã, conferindo às unidades escolares: Autonomia Pedagógica: para elaborar seu Plano de Desenvolvimento Estratégico e seu Projeto Político-Pedagógico, definir parcela do currículo, decidir sobre o uso ou não do livro didático e sua eventual escolha, definir sobre material de ensino e acervo bibliográfico, elaborar o calendário escolar, estabelecer intercâmbios culturais e científicos, elaborar modelo de avaliação da aprendizagem. Autonomia para Gestão de Pessoal: para atribuição de classe/aula, avaliar o desempenho, promover cursos de atualização, aperfeiçoamento e reciclagem, a partir de critérios estabelecidos em Conferência Municipal Escolar, referendada pelo Conselho Municipal e pelo Conselho Deliberativo. Autonomia Administrativa: para organizar e normatizar o funcionamento da escola, a administração e o gerenciamento da vida escolar. Autonomia financeira: para definir despesas de custeio, plano de aplicação dos recursos disponíveis, contratação de pequenas obras, bens e serviços.

O conceito de sistema adotado na proposta do Sudeb considera a escola, de um certo modo, como um verdadeiro sistema: ela é uma unidade estruturada de partes constitutivas, interdependentes, nas quais interagem sujeitos do fato pedagógico, de acordo com as normas pautadas (pactuadas ou impostas) de funcionamento e objetivos que devem ser buscados pelo conjunto. O Sudeb conceitua-se como um processo de integração dos poderes constituídos, a interação política, normativa e executiva dos serviços públicos de educação básica, a fusão dos recursos financeiros, tecnológicos, materiais e humanos, a unificação das redes escolares sem distinção de unidades federais, estaduais ou municipais, localizadas no território do estado, de modo a evitar os paralelismos, as discriminações no atendimento dos alunos e no trato com os profissionais de educação, a duplicidade de meios para fins idênticos e as atividades concorrenciais, buscando a universalização da educação básica de qualidade para todos os habitantes do estado.

As críticas do sindicato dirigiram-se ao modo como o termo de referência foi elaborado pela Seduc, unilateralmente, com a assessoria do Instituto Paulo Freire, ${ }^{7}$ e à descentralização preconizada. Consideramos que o sistema descentralizado proposto engendrava a pulverização das redes, ao invés de viabilizar o Sistema Único, pela caracterização do conceito adotado e pelas atribuições conferidas à escola. A descentralização preconizada não democratizava o poder, haja vista o próprio modo como a proposta do Sudeb foi elaborada. Insere-se na dinâmica paradoxal nas reformas educacionais, segundo expressão de Gentili: as lógicas articuladas 
de descentralização-centralizante e de centralização-descentralizada empreendem-se medidas descentralizadoras maldizendo-se o planejamento estatal e os efeitos improdutivos das burocracias estatais e sindicais. Transferem-se instituições escolares da jurisdição federal para a estadual e desta para a esfera municipal (municipaliza-se o sistema de ensino). Propõe-se repassar o fundo público para níveis cada vez mais micros, inclusive a própria escola; desarticulam-se mecanismos unificados de negociação com as organizações dos trabalhadores da educação; flexibilizam-se as normas de contratação, carreira e remuneração. E ao mesmo tempo centralizam-se certas funções que não são transferidas, como foi o estabelecimento de parâmetros para o Sistema Único (1996).

Consideramos, preponderantemente, com Arroyo \& Abicalil, que é necessário lutar pela autonomia da escola, dos seus profissionais e da comunidade escolar diante do seu atrelamento aos interesses privatistas do clientelismo político, entretanto não se pode contrapor à gestão centralizada uma soma de escolas autônomas, desmantelando o sistema escolar. Partimos da necessidade de um projeto coletivo de sociedade, construído nos partidos, nos sindicatos e nos movimentos sociais, pelo qual exigimos, de um governo democrático, que dê direção e legitimidade política a esse projeto (1996a).

\section{A construção do Sistema Único como investimento na qualificação para a proposição do orçamento público}

Para definir o Sistema Único o Sintep-MT defende a automatização do repasse dos recursos constitucionalmente vinculados à educação, que irá definir a criação do Fundo de Manutenção e Desenvolvimento da Educação Pública Básica. Um Fundo Único para o Sistema Único, com recursos do estado e dos municípios aderentes. Com a vinculação mínima prevista na Constituição estadual (35\%) para dar conta de toda a educação básica infantil, fundamental e média - de qualidade, democrática, gratuita e universal. Para estabelecer se os recursos são suficientes é preciso demonstrar os custos. Junto com a automatização dos recursos é mister fixar o custoaluno-qualidade, calculado com variações que supõem um Plano de Desenvolvimento do Sistema Único. A proposta, com a metodologia da CNTE, considera o custo-aluno sob quatro tipologias distintas, até alcançar o custo-aluno-qualidade. Custo-aluno-realizado - resultado da divisão das despesas com manutenção e desenvolvimento do ensino pelo número de alunos diretamente beneficiados no sistema. Obtém-se pela análise dos balanços anuais (despesas) do estado e dos municípios e pelas estatísticas 
de matrículas na rede pública. Como o perfil das despesas muda anualmente, a média deve ser indicada pela análise de um período consecutivo de dez anos ou mais. Se o custo-aluno só considerar esta realidade e parar por aqui, o resultado é trágico: quanto mais crescer a escolarização, menor será o volume de dinheiro por aluno disponível. Custoaluno-potencial-atual - resultado da divisão das receitas vinculadas dos impostos, transferências, salário-educação e contribuição social pelo número de alunos matriculados, descontadas as verbas destinadas ao ensino superior no último exercício financeiro. Custo-aluno-potencial-futuro - resultado da divisão da previsão de receitas, embutindo um porcentual de recuperação fiscal pelo número de matrículas previstas para o período em questão, definidos nos Planos Municipais e no Plano Estadual de Educação pelos Fóruns de Política Educacional. Custo-aluno-qualidade - definidos os componentes da qualidade do ensino necessário (salário, jornada e carreira dos profissionais da educação, profissionalização e formação continuada, material didático, equipamentos, áreas e imóveis para diversas atividades, incorporação de novas tecnologias, mobiliário etc.) e os parâmetros de organização de ensino (número médio de alunos por classe, relação do número de alunos por professor, número de alunos por funcionário, extensão e atribuições das equipes técnicas, horário de funcionamento das escolas, calendário, sistemas de apoio etc.), pesquisar-se-iam os preços médios anuais na proporção dos alunos previstos no sistema.

\section{O desafio de envolver a sociedade no acompanhamento das contas do governo}

Os recursos do Fundo Único constituirão a Fundação do Sistema Único de Ensino Público Básico, e serão administrados por um Conselho Gestor de composição paritária tripartite: 1/3 composto pelo Poder Público (estado + prefeituras aderentes); $1 / 3$ composto pelos serventuários (professores e funcionários da educação pública básica/ Sintep); 1/3 composto por usuários (pais, mães, alunos e alunas das escolas públicas integradas no Sistema Único). Todos eleitos por seus respectivos segmentos e nomeados pelo secretário de estado da Educação. O Conselho Gestor administra o Fundo e todo o patrimônio incorporado à Fundação pela atual Rede Estadual e pelas Redes Municipais aderentes, a gestão de pessoal e educacional (formação continuada, profissionalização, avaliação institucional, registros, política de modernização). Em cada município se cria um Conselho Municipal similar para acompanhar a aplicação dos recursos do Fundo Único, indicar as prioridades de 
atendimento para expansão do sistema, manutenção e ampliação das estruturas físicas e dos equipamentos, formação continuada e profissionalização, a partir dos Planos Escolares e que fiscalizará seu cumprimento pelos Conselhos Deliberativos.

A Fundação do Sistema Único de Ensino Público Básico é a instituição criada para abarcar e administrar simultaneamente recursos e patrimônios das atuais Redes Estadual e Municipais: capaz de dar unidade ao financiamento, à gestão, à política de expansão, de formação continuada, de avaliação sistêmica e de planejamento global. O Estado de Mato Grosso, o proponente do Sistema Único, deve integrá-lo com todos os recursos vinculados e com toda a sua atual rede. Os municípios que o fizerem por adesão, do mesmo modo, ingressam com todos os seus recursos vinculados e com toda a sua respectiva rede.

\section{A aplicação dos recursos}

Os recursos destinados a pagamento e contratação de pessoal das escolas públicas serão geridos pela Fundação do Sistema Único, instituição pública organizadora dos sistemas e empregadora de todos os trabalhadores envolvidos nas atividades docentes, nutricionais, de limpeza, de administração, inovações tecnológicas e multimeios didáticos, e segurança das escolas do sistema. Os recursos para manutenção, expansão da rede, ampliação, compra de equipamentos e materiais de uso permanente vão diretamente para as escolas, de acordo com as prioridades de atendimento fixadas pelos Conselhos Municipais a partir dos planos escolares elaborados e administrados pelos Conselhos Deliberativos.

\section{O dinheiro que vai para a escola}

Não compete a cada escola, isoladamente, as demandas salariais dos profissionais da educação, a estrutura de carreira única, o ônus das contribuições sociais, a forma de contratação do pessoal necessário para o desenvolvimento direto e cotidiano das atividades escolares. Essas devem ser preocupações de todo o sistema. Cada escola não é uma ilha. A escola receberá mensalmente o necessário para a conservação e limpeza do prédio, dos equipamentos e das instalações, para compra de materiais didáticos e administrativos, para obras e ampliações propostas pelo Conselho Deliberativo e aprovadas no âmbito do Conselho Municipal, para compra de equipamentos previstos no seu Plano Estratégico e necessários ao seu Projeto Político-Pedagógico. 
A regulamentação, que não é bem-vinda no neoliberalismo, tem sido a única forma de afirmar direitos e assegurar a luta por suas garantias. A gestão democrática é para garantir direitos e tornar transparente a aplicação dos recursos. Por isso a gestão democrática deve abarcar todos os níveis do Sistema Único. É necessária uma lei estadual sobre a gestão de todo o sistema. Sem essa lei, não só os Conselhos podem responder por responsabilidades que não são suas como podem alterar sua constituição e suas competências, por meio de uma simples assembléia não regulamentada. Sequer há a garantia de que para cada escola haja somente um Conselho Deliberativo. É preciso ter presente as dissidências não regulamentadas e as disputas de representação. A lei deve fixar as competências e atribuições dos Conselhos em cada nível: escolar, municipal e estadual; os membros constitutivos de cada conselho; os segmentos dos Conselhos Deliberativos e a composição dos Conselhos Municipal e Estadual; as competências, atribuiç̃oes e composição do Conselho Estadual de Educação, normatizador do Sistema Único, das redes particulares, das instituições de ensino superior não-universitárias; as formas e os processos eleitorais de cada conselho e dos diretores de escola, válidos para todo o Sistema Único; a eliminação de qualquer processo seletivo institucional prévio, como as atuais e duvidosas provas de avaliação da "competência" dos candidatos e a indicação da Seduc dos "melhores" (prática que fora adotada); o impedimento legal de qualquer iniciativa que fira os princípios de gratuidade e universalidade da educação pública básica; as cláusulas pétreas que não podem ser alteradas por assembléias escolares estatutárias para efeito de registro dos conselhos escolares como entes jurídicos; os procedimentos gerais de prestação de contas e aplicação dos recursos do sistema Único.

\section{A estratégia de discussão}

A partir de Conferências Escolares, ascendendo para Conferências Municipais e Regionais, culminando com a Conferência Estadual, podemos construir espaços político-pedagógicos que darão substância, legitimidade política e que comprometam os atores envolvidos nas mudanças necessárias para o reordenamento do sistema. A melhor forma de organizar o debate democrático é respeitando a proporcionalidade e a paridade da representação dos segmentos escolares e setores sociais envolvidos em cada instância do debate já mencionadas. Este procedimento poderá protagonizar atores sociais, que por não pretenderem falar em nome da 
"sociedade como um todo", mas em nome das diferenças, contribuirão para que as diferenças sejam reconhecidas e respeitadas; consolidar uma estratégia que não se prenda à formulação encomendada a especialistas de fora da experiência cotidiana das escolas, destacando os valores, as experiências e formulações oriundas de suas próprias histórias, para pensar regras e procedimentos institucionais sem o reducionismo puramente técnico.

Nas Conferências Escolares (a instância de participação mais universal): participam todos os pais e as mães, alunos(as), funcionários(as), professores(as), coordenadores(as), assessores(as) para cada 600 alunos matriculados. Nas Conferências Municipais: participam 1 (um) representante por segmento escolar, eleito nas Conferências Escolares, para cada 600 alunos matriculados, mais os assessores pedagógicos do estado e dos municípios e o representante das instituições de ensino superior ligadas à formação de professores com atividades no município. Nas Conferências Regionais: participam 1 (um) representante de cada segmento, para cada 1.200 alunos matriculados na rede pública da região, eleito nas Conferências Municipais, mais os assessores pedagógicos do estado e dos municípios e o representante das instituições de ensino superior ligadas à formação de professores com atividades na região. Na Conferência Estadual: participam 1 (um) representante por segmento escolar, para cada 2.400 alunos matriculados na rede pública, mais 1 (um) assessor pedagógico do estado, 1 (um) dos municípios e 1 (um) das instituições de ensino superior ligadas à formação de professores eleito em cada Conferência Regional.

Em cada instância de representação, será assegurado pelo menos 1 (um) representante de cada segmento para fração superior a 0,5 no resultado da aplicação do respectivo coeficiente de proporcionalidade.

\section{Um modo de conclusão}

Não tivemos um Sistema Único de Educação como produto final desse processo. Mas podemos compreender um pouco mais sobre a luta pela sua viabilização. Os consensos criados, apesar de não cumpridos, num lapso de tempo, mostraram que as políticas educacionais podem ser pensadas de outra forma. Que possamos recompor a memória dessa experiência a partir da insistência na não-neutralidade da educação e no engajamento político daqueles e daquelas que a fazem, seja na condição de educadores ou de educandos. 


\section{Recebido em março de 2000. \\ Reformulado em março de 2001. \\ Aprovado em junbo de 2001.}

\section{Notas}

1. Pressupomos a vigência do neoliberalismo conforme Gentili em "Neoliberalismo e educação: Manual do usuário", in: Escola S.A.: Como construção hegemônica, uma alternativa de poder constituída por uma série de estratégias políticas, econômicas e jurídicas, orientadas para encontrar uma saída dominante para crise capitalista iniciada no final dos anos 60; e um projeto de reforma ideológica que constrói e difunde um novo senso comum para dar sentidos às reformas impulsionadas. O neoliberalismo impõe uma dinâmica de mudança material e uma dinâmica de reconstrução discursivo-ideológica da sociedade.

2. Uma indicação importante é o trabalho de Raichelis em sua análise sobre Esfera pública e Conselhos de Assistência Social.

3. A revista Teoria e Debate $\mathrm{n}^{-1}$ 46, nov./dez. 2000/jan. de 2001, traz um balanço das eleições que pode indicar cenários novos e favoráveis ao PT e a sua política de alianças nas próximas eleições estaduais e nacional.

4. Tenho presente o balanço das privatizações feito por Biondi em $O$ Brasil privatizado: Um balanço do desmonte do Estado.

5. Até aquele momento a Constituição Estadual, no inciso III do artigo 237, assegurava: valorização dos profissionais de ensino, garantida na forma da lei; plano de carreira para o magistério público, com piso salarial profissional; jornada de trabalho de no máximo quarenta horas, sendo metade destinada a planejamento e estudos extraclasse. A emenda constitucional $\mathrm{n}^{\mathrm{a}} \mathrm{12}$, de 16 de setembro de 1998, modificou o dispositivo, que passou a vigorar nos seguintes termos: jornada de trabalho única de 30 horas, sendo $1 / 3$ destinado a planejamento e estudos extraclasse.

6. Paulo Freire ensinou que o direito de criticar, em termos construtivos, requer o testemunho educativo e uma posição rigorosamente ética (1993). Devo mencionar que nesta experiência briguei muito e já me reconciliei muito (tendo a certeza de que brigaremos muitas outras vezes), com Carlos Maldonado, que atualmente é secretário de Educação no município de Cuiabá (2001), a quem agradeço as oportunidades de interlocução. Carlos Maldonado foi convidado pelo governador Dante de Oliveira a deixar a Secretaria da Educação após os resultados dos trabalhos das Conferências. Ainda não estou reconciliada com o secretário Valter Albano, que é secretário de estado da Fazenda (2001), pessoa que muito respeito. Ambos, além de terem me concedido entrevista durante meu trabalho de dissertação, são indispensáveis em quaisquer debates crítico-propositivos sobre a Política Educacional no Mato Grosso.

7. Ao termo de referência acompanharam uma proposta de emenda constitucional a todo capítulo da educação e uma proposta de reestruturação da carreira, desconsiderando os trabalhos de uma comissão paritária designada pelo próprio governo. A proposta de emenda constitucional a todo capítulo da Constituição Estadual foi considerada, pelo sindicato, como a raiz do Sistema Único Descentralizado. Registramos que não é preciso modificar a Constituição Estadual para construir o Sistema Único, é preciso cumpri-la regulamentando o artigo 244 que o propõe. A adoção da descentralização, num contexto de desregulamentação, de desestatização e de precarização das relações de trabalho, tem sido parte constitutiva do processo de desestatização. A crítica ao modelo decorre da luta pela manutenção dos serviços públicos necessários sob a responsabilidade do estado. 
ABICALIL, Carlos A. Proposições pontuais para debate e aprofundamento. Seminário da Diretoria Central Sintep-MT, Cuiabá, 14 e 15 de dezembro de 1994 (datilografado).

ALBANO, Valter. Proposta de uma política educacional para o Estado de Mato Grosso. Cuiabá, 1995 (datilografado).

ARROYO, Miguel. "Educação e exclusão da cidadania". In: Buffa, E.; Arroyo, M.; Nosella, P., Educação e cidadania: Quem educa o cidadão? São Paulo: Cortez, 1996.

ARROYO, Miguel; ABICALIL, Carlos A. Qualidade na educação. Revista de Educação, Apeoesp, São Paulo, 1996, nª 8, p. 55-66.

AVELAR, Lúcia. Clientelismo de Estado e política educacional brasileira. Educação \& Sociedade, Campinas: Cedes, 1996, nª 54, p. 34-49.

BIONDI, Aloysio. O Brasil privatizado: Um balanço do desmonte do Estado. São Paulo: Fundação Perseu Abramo, 1999.

BOBBIO, N. et al. Dicionário de política. Brasília: Editora da UnB, 1999.

BOBBIO, N.; BOVERO, M. Sociedade e Estado na filosofia política moderna. São Paulo: Brasiliense, 1994.

. O futuro da democracia: Uma defesa das regras do jogo. São Paulo: Paz \& Terra, 1992.

CHAUI, M. Conformismo e resistência: Aspectos da cultura popular no Brasil. São Paulo: Brasiliense, 1994.

. Cultura e democracia. São Paulo: Cortez, 1993.

CUNHA, Luís A.; MILHOMEM, Gumercindo. Educação e sindicalismo: Uma equação democrática? Revista de Educaşão, Apeoesp, São Paulo, 1996, nª 8, p. 10-19.

FRENTE Cidadania e Desenvolvimento. Plano de Metas Mato Grosso 1995-2006: Programa de Governo (estudos preliminares). Cuiabá (MT), 1994. 
FREIRE, Paulo. À sombra desta mangueira. São Paulo: Olho Dágua, 1995.

. Política e educação. São Paulo: Cortez, 1993.

FRIGOTTO, G.A. "Formação e a profissionalização do educador: Novos desafios". In: Silva, T.T. \& Gentili, P., Escola S.A.: Quem ganha e quem perde no mercado educacional do neoliberalismo, Brasília: CNTE (Confederação Nacional dos Trabalhadores em Educação), 1996.

"Os delírios da razão: Crise do capital e metamorfose conceitual no campo educacional”. In: GenTiLI, P. (Org.), Pedagogia da exclusão: Crítica ao neoliberalismo em educação. Rio de Janeiro: Vozes, 1995.

GENTILI, Pablo. "Neoliberalismo e educação: Manual do usuário". In: Gentili, P. \& Silva, T.T. (Orgs.), Escolas S.A.: Quem ganha e quem perde no mercado educacional do neoliberalismo. Brasília: CNTE (Confederação Nacional dos Trabalhadores em Educação), 1996.

GENRO, Tarso; SOUZA, Ubiratan. Orçamento participativo: A experiência de Porto Alegre. São Paulo: Fundação Perseu Abramo, 1997.

KENSKY, Vani Moreira. Perspectivas internacionais na formação docente. Campinas: Faculdade de Educação, Unicamp, 1995 (datilografado).

MONLEVADE, J.A.; FERREIRA, E.B. O Fundef e seus pecados capitais. Ceilândia (DF): Idea, 1997.

PRESTES, Maria da T. "Políticas educacionais em contextos populares". In: Neto, José F. de Melo \& Scocuglia, Afonso C., Educação popular: Outros caminhos. João Pessoa: Editora Universitária/ UFPB, 1999.

RAICHELIS, Raquel. Esfera pública e Conselbos de Assistência Social: Caminhos da construção democrática. São Paulo: Cortez, 1998.

RODRIGUES, Leôncio M.; OLIVEIRA, Marco A. O movimento sindical no cenário do neoliberalismo. Revista de Educação, Apeoesp, São Paulo, 1996, nª 8, p. 3-9. 
SEDUC-MT, Secretaria de Estado da Educação. Educação no Estado de Mato Grosso, Realidade e Propostas. Cuiabá-MT, 1995. . Sistema Único Descentralizado de Educação Básica (Sudeb). Cuiabá-MT, 1996.

SINTEP. VIII Congresso Estadual: Educação, Trabalho e Cidadania. Cuiabá: Sintep-MT, 1994.

. Sistema Único de Educação Pública Básica para Mato Grosso: A formulação do Sintep-MT. Cuiabá: Sintep-MT, 1996.

SILVA, José Dirceu de O.; IANONI, Marcus. Reforma política, instituições e democracia no Brasil atual. São Paulo: Fundação Perseu Abramo, 1999. 